\title{
Multiple electroconvulsive shocks and feeding and drinking behavior in the rat
}

\author{
MICHAEL J. PREWETT \\ East Carolina University School of Medicine and Pitt County Mental Health Center \\ Greenville, North Carolina 27834 \\ and \\ PAMELA K. VAN ALLEN and JOEL S. MILNER \\ Western Carolina University, Cullowhee, North Carolina 28723
}

\begin{abstract}
Daily food and water intakes of 22 male rats were measured during a 4-week habituation period. After habituation, animals were administered a series of five electroconvulsive shock (ECS) treatments, one per day for 5 days. Daily food and water intake measurements were continued during ECS treatments and for 11 days following the last shock. Comparing the last preand the first post-ECS treatment days, a significant decrease in both food and water intake was found. Food and water intakes required 8 to 10 days to return to pre-ECS treatment levels.
\end{abstract}

Investigators (Prewett \& Milner, 1977) have studied the effects of electroconvulsive shock (ECS) on feeding and drinking behavior in the rat. They report a single ECS produces a significant decrease in both food and water intake. Following one shock, rats required 3 days to return to baseline levels of food and water consumption.

The decrease in water intake with a subsequent three-day recovery period observed by Prewett and Milner (1977) is supported by biochemical changes that occur following administration of ECS. Acetylcholinesterase (AChE), a cholinergic antagonist, appears to increase following one ECS and, subsequently, returns to baseline after 3 days (Adams, Hoblit, \& Sutker, 1969). The decrease in food intake reported by Prewett and Milner (1977) can also be correlated with biochemical changes in the brain. ECS is reported to produce changes in the adrenergic system, albeit the nature and direction of the changes remain unclear (Schildkraut \& Draskoczy, 1974). A determination of the effect of ECS on cholinergic and adrenergic systems is important because blockage of cholinergic and adrenergic activity in the rat is known to decrease water and food intake, respectively (Coury, 1967; Grossman, 1962; Miller, Gottesman, \& Berry, 1964).

The present study was designed to supplement and extend the initial findings of Prewett and Milner (1977) by investigating the effects of multiple ECS treatments on food and water intake in the rat. The time required for recovery from multiple ECS treatment was also investigated.

This research was supported, in part, by a grant from the Western Carolina University Grants-In-Aid program. Send reprint requests to Joel S. Milner, Department of Psychology, Western Carolina University, Cullowhee, North Carolina 28723.

\section{METHOD}

\section{Subjects}

The subjects were 22 naive male Sprague-Dawley albino rats. All animals arrived in the laboratory at 70 days of age and were housed individually in stainless steel cages measuring $40 \mathrm{x}$ $24 \times 19 \mathrm{~cm}$ under constant light conditions. Throughout the experiment, rats were maintained on an ad-lib food and water schedule.

\section{Apparatus}

A Grason-Stadler shocker was employed to deliver ECS that consisted of a $30-\mathrm{mA}$ constant current of .5 -sec duration delivered via saline-soaked, gauze-covered ear clips. During the study, all rats were presented powdered Purina laboratory chow in standard Wahmann food cups and distilled water in 100-ml graduated glass drinking cylinders. Food measures were made to the nearest $.10 \mathrm{~g}$ and water measures were taken to the nearest milliliter.

\section{Procedure}

Animals were allowed to habituate to the laboratory facilities for 4 weeks prior to ECS treatments. During the habituation period, food and water intakes were recorded at 24-h intervals.

Following the habituation period, ECS treatments were administered on 5 consecutive days immediately following recording of food and water intakes on each day. After ECS treatments were completed, 24-h measurements of food and water intakes were recorded for 11 days.

\section{RESULTS AND DISCUSSION}

Mean daily food and water intakes for all subjects across 5 pre-ECS, 5 ECS, and 11 post-ECS days are shown in Figures 1 and 2, respectively. The Wilcoxon matched-pairs signed-ranks test was employed to evaluate intake changes between the last pre- and the first post-ECS treatment days. ECS produced a significant inhibitory effect for both food intake $(\mathrm{T}=1.5, \mathrm{~N}=22$, $\mathrm{p}<.001)$ and water intake $(\mathrm{T}=4, \mathrm{~N}=22, \mathrm{p}<.001)$. 


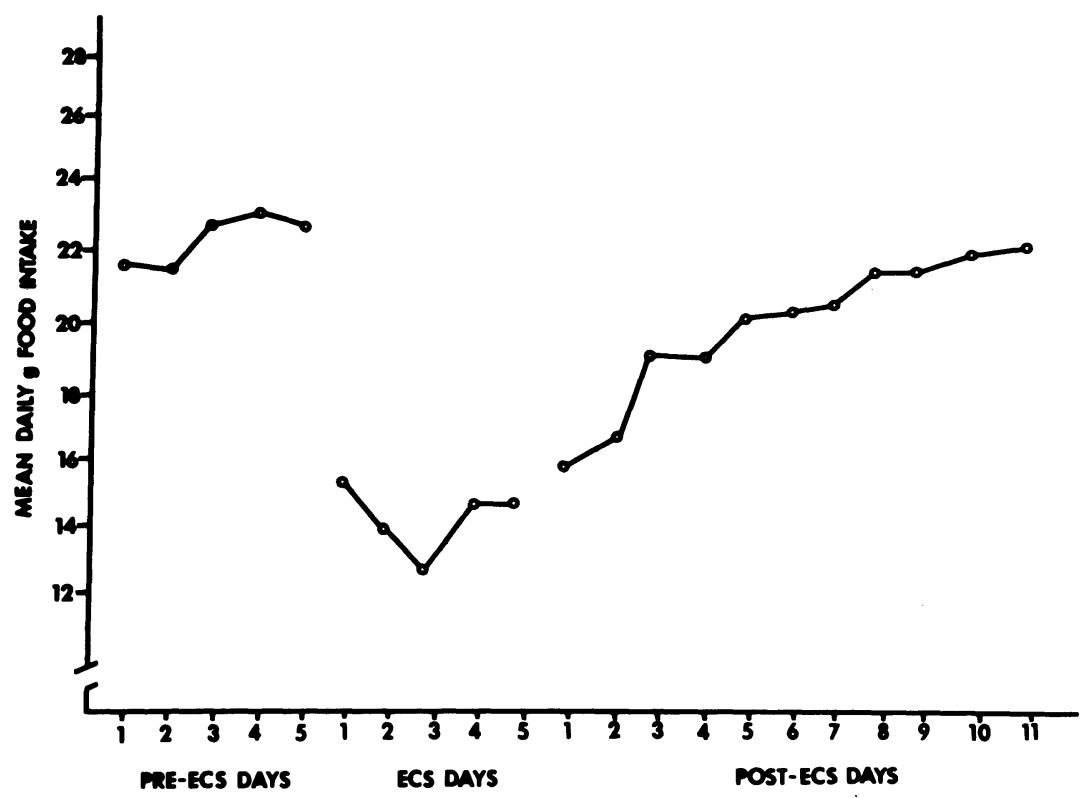

Figure 1. Mean daily food intake across 5 days pre-ECS, 5 ECS treatment days, and 11 days post-ECS.

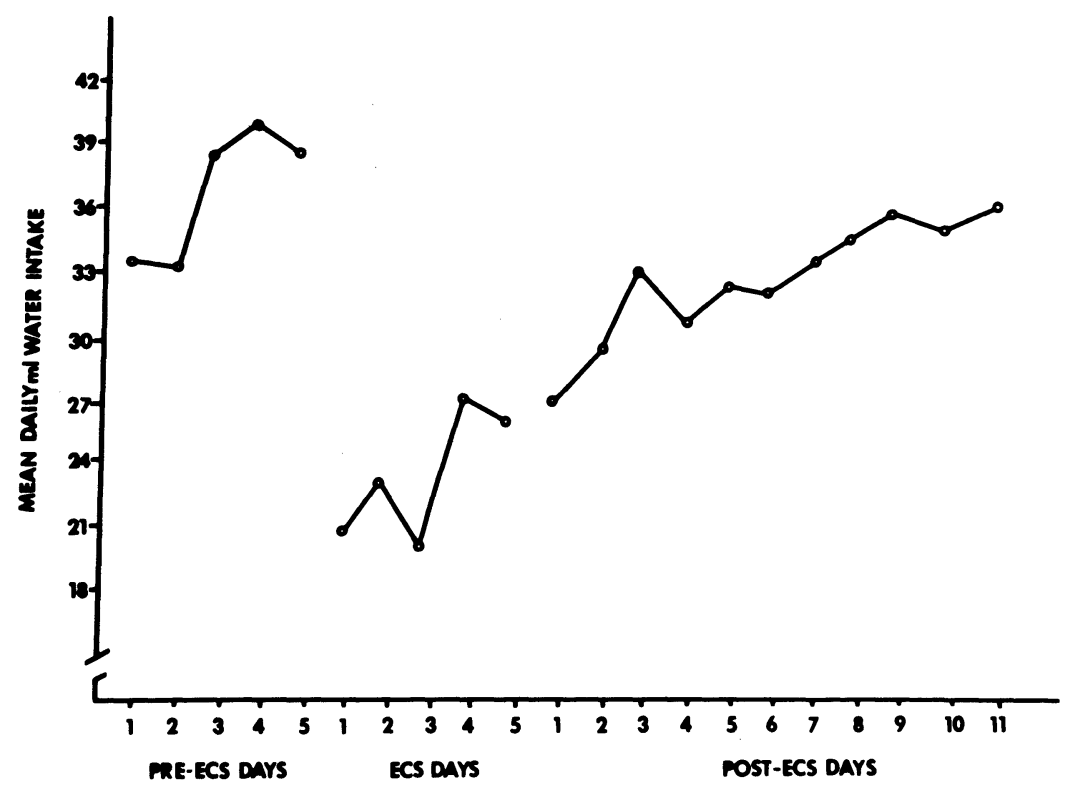

Figure 2. Mean daily water intake across 5 days pre-ECS, 5 ECS treatment days, and 11 days post-ECS.

Although only the last pre- and the first post-ECS treatment days were employed in the statistical test, the graphic data presented in Figures 1 and 2 suggest that the suppression effect resulting from multiple ECS was prolonged. Prewett and Milner (1976) reported that following one ECS treatment, animals required 3 days to return to baseline levels of feeding and drinking. Animals in the present study required 8-10 days to return to baseline levels of food and water intake.

The present data indicate food consumption was reduced to lower levels than those previously reported.
Prewett and Milner (1977) found a 15\% decrease in food intake following a single ECS treatment, whereas the present study showed a 36\% decrease following five ECS treatments. The additional decrement in water intake following multiple shocks was not as great as that observed for food intake. While a single shock produced a $26 \%$ decrement in water consumption, water intake was reduced $32 \%$ after five ECS treatments.

In conclusion, the present data suggest that the inhibitory effects of repeated ECS treatments on feeding and drinking behavior are to some degree cumulative. 
Further, multiple ECS treatments produce decrements in daily food and water intakes which require 8-10 days to return to baseline. The physiological and biochemical changes that underlie ECS-induced changes in feeding and drinking behavior remain to be delineated.

\section{REFERENCES}

Adams, H. E., Hoblit, R. R., \& SutKeR, P. B. Electroconvulsive shock, brain acetylcholinesterase activity, and memory. Physiology \& Behavior, 1969, 4, 113-116.

Coury, J. N. Neural correlates of food and water intake in the rat. Science, 1967, 156, 1763-1765.
Grossman, S. P. Direct adrenergic and cholinergic stimulation of hypothalamic mechanisms. American Journal of Physiology, $1962,202,872-882$.

Miller, N. E., Gottesman, K. S., \& Berry, N. Dose response to carbachol and norepinephrine in rat hypothalamus. American Journal of Physiology, 1964, 206, 1384-1388.

Prewett, M. J., \& Milner, J. S. Effects of electroconvulsive shock on food and water intake in the rat. Physiology \& Behavior, 1977, 19, 341-343.

SchildkRaut, J. J., \& Draskoczy, P. R. Effects of electroconvulsive shock on norepinephrine turnover and metabolism: Basic and clinical studies. In M. Fink, S. Kety, J. McGaugh, \& T. Williams (Eds.), Psychobiology of convulsive therapy. Washington, D.C: V. H. Winston, 1974.

(Received for publication May 1, 1978.) 